\title{
Study on Community Pension Model in the Field from Multiple Governance Perspective
}

\author{
Wenjing Wang \\ Department of Politics and Law, Northeast Normal \\ University \\ Changchun, P.R. China 130117
}

\author{
Lihua Li \\ Department of Politics and Law, Northeast Normal \\ University \\ Changchun, P.R. China 130117
}

\author{
Chuanrui Chen \\ Department of Politics and Law, Northeast Normal University \\ Changchun, P.R. China 130117
}

\begin{abstract}
Based on the survey of community pension service in Changchun city, this paper summarizes and evaluates the current pattern of community pension service in Changchun, including the model of community day care and the home care institution. We also construct the community pension service model from multiple governance perspective. Last but not least, based on this model, some related policy recommendations are proposed to better provide public services for the elderly.
\end{abstract}

Keywords-Community pension; Multiple governance; Pension services

\section{INTRODUCTION}

The aging population has been continuously increased since China entered an aging country in 2000. According to the statistics of the National Bureau of Statistics, by the end of 2015, China's population over 60 years old has reached 221 million, accounting for $16 \%$ of the total population, and the elder over the age of 60 are increasing at a rate of more than $5.4 \%$ each year, it is expected that by 2050 , people aged over 60 will account for about $34 \%$ of the total population. Among them, the elder aged 80 years old and above will reach 94.48 million, accounting for $21.78 \%$ of the elder population. The size of the elder population is growing in proportion and expansion, and the burden of population support is gradually increasing. As the Chinese adage goes "To let the old have someone to depend on with a treasure sense of security", and it is related to the people's livelihood and the country's longterm stability. As an important issue for people's livelihood, providing for the aged has attracted widely attention from the government and society.

People's pension needs are increasingly diversified because of population aging. Traditional family pensions and institutional pensions are faced with many difficulties and they can't meet current pension needs. With its own characteristics and advantages, Community Pension Service Model has become an important trend for aging and pension problems in China in present and future. There are many practices in how to provide community pension services, at the same time, there are new problems in the current community pension service model, such as, the relationship between communityrelated old-age care subjects, the ignorance of the self-help and mutual assistance among the old-age groups, and lack of volunteers to participate in the long-term mechanism of community care services [1-2]. This paper attempts to solve a series of problems in the Community Pension Service Model from multiple governance perspective, and based on this, it tries to build a Community Pension Service Model from multiple governance perspective.

\section{CuRRENT SituATION AND BASIC MODELS OF COMMUNITY PENSION SERVICES IN CHANGCHUN}

In order to fully understand the basic situation of community pension services in Changchun, we visited the Community Management Committee and the "Happiness" home-based care center in Changchun in 2017 .We investigated elderly through questionnaires for Community pension service .we visited 10 communities in the 4 districts of Nanguan District, Jingyue District, Chaoyang District and Erdao District in Changchun. 200 questionnaires were distributed, of which 186 were valid.

\section{A. The basic needs of community pension services in Changchun}

According to the survey, $61.54 \%$ of the elderly are living with their children, $28.21 \%$ of them are living with a spouse, and $10.26 \%$ of elderly people live alone. Elderly people living with their children can enjoy family care directly. Those living with their spouses or living alone can take care of themselves. In respect of the attitude towards community pension, $65.4 \%$ of the elderly are willing to accept community pension services, $22.1 \%$ says it all depends, and $12.5 \%$ are unwilling. It's seen that most of them support community pension service. In the interview, it's learned that more than half of the elderly people enjoyed the community pension services in real life to some extent, such as outdoor fitness facilities, activity rooms of elderly activity centers, etc., and they said that they will

This research was financially supported by National Social Science Youth Fund Project (Grant No.: 14CG075). 
continue to enjoy services here. Therefore, it can be seen that the elderly have certain needs for community pension service.

\section{B. Multiple differences in the need of aged care services.}

According to the data, the need from high to low is: medical services (62\%), fitness and entertainment (34\%), chatting (34\%), care activities (30\%), learning activities (22\%) and legal aid (16\%). Moreover, the need for medical services is related to age and economic conditions. The older the age the worse the financial situation,and the greater the demand for medical services; the need for medical services is focused on regular medical examinations, daily health care and health education. The demands for care activities is mainly catering, and there are others such as cleaning, laundry ,repairing and so on. Therefore, in the provision of aging care services, different elderly people should be given different service according to their different demands [3].

\section{The basic model of community pension services}

\section{1) Community Day Care Model}

Community Day Care Model refers to the community elderly day care station or service center established by the financial subsidy of the Changchun Municipal Government in the community. The community staff manage and provides services to the day care stations and service center which are ways of providing service to elderly people. Among the interviewed 10 communities, 6 communities have established day care stations ( 2 communities have begun to explore the model of home care services, and another two communities have not set up day care stations because of finance). With the encouragement of the Changchun Municipal Government to build community day care centers for the elderly in 2009, this model was set up and has begun to take shape.In the community where the day care stations runs better, there are usually have special activity centers for the elderly, such as fitness equipment, table tennis rooms, dance rooms, musical instrument rooms, chess and card houses. At present, most communities have been established by government and are developing steadily. The number of elderly people attending elderly service centers has also increased, and the quantities and quality of services have also promoted.

\section{2) Home Care Institution Model}

This model is illustrated by the example of the first "customized" service pilot --- "Happiness" home care service center in Jilin Province. "Happiness" home care service is located in Lingdong Community on Rongguang Street in the Erdao District in Changchun. It adheres to the concept of "customized" service, taking enterprises as the main body, relying on the street and community pension facilities, and on the premise of information collection, ability evaluation and service designing of the aged. The Home Care Institution Model provides "package type" service to the elderly at home by combining government purchase service and market operation. The operation mode is "government commitment, fixed delegation, contract management, and evaluation cashing."
The mode of home care service agency is still in the pilot and start stage in Changchun, and there is only "Happiness" home care service center in Changchun. From the formal operation in September 2014 to May 2015, more than 700 elderly people signed an agreement with the center. The agreement is signed every month, and the elderly will enjoy the service after signing the agreement. At the end of the month, the government pays 200 yuan for each old man, and over 200 yuan is paid by the old man themselves; enterprise has achieved balance of payments currently. With the growth of the consumption potential of the elderly, the home pension institutions have good expectations and prospects.

\section{CONSTRUCTION OF COMMUNITY PENSION SERVICE MODEL FROM MULTI-GOVERNANCE}

\section{A. Role setting of multiple subjects}

\section{1) Community - Leading and Coordinating}

The community will play an important role undoubtedly[4]. The community mainly plays a leading and coordinating role in Community Pension Service from Multiple Governance. The leading role of the community is reflected that the community is the main provider of community pension services. The community pension is developed based on the community, the elderly live in the community, and the community manages the basic information of the community residents, and the operation of various resources of the community must rely on the management and coordination of the community. The community provides public pension services for all the elderly in the community. The Community Health Service Center regard the elderly people as the service focus, establishing health records for the elderly in the community, and providing medical services such as prevention, health care, medical treatment, rehabilitation, and health education. The elderly activity room and day care room provide fitness, entertainment, learning and simple care to the elderly. At the same time, the community plays a role in resource integration. The community pension is based on the community as a carrier, and it is at a central coordination point compared with other related entities. For the government, the community is the specific implementation of the policy; for the elderly, it's a service provider; for social organizations, it's a liaison and a cooperation, as a result, the community needs to coordinate with these subjects. The community health service center regards the elderly as the service focus, establishing health records for the elderly in the community and providing medical services such as prevention, health care, medical treatment, rehabilitation, health education and so on. Geriatric activity rooms and day care rooms provide fitness, entertainment, learning and simple care activities for the elderly. At the same time, the community has the function of integrating resource, the community providing for the aged takes the community as the main carrier, compared with other relevant subjects, it is in a central coordination point; the community is the specific implementation of the policy that formulated by government, and is the service provider for old people, also has relationship of contact and cooperation with social organization, and the community needs to coordinate the relationship with these subjects. 
2) Government_-Policy Formulation and Financial Support

The community provides specific community pension service under the guidance of policy which formulated by government. The government plays an important role in making policy of the pension and the change of policy influences the supply way and level of the pension service. In addition, as a public service, the old-age service needs the financial support by the government, the construction and operation of the community day care room for the elderly need financial support, Governments need gives enterprise preferential policies and financial subsidies when the governments purchase old-age care services from the market. With the control of authority and resources, the government can organize communities and social supporting forces from all levels of society to help community pension effectively. Supportive policies and financial support are the most important ways to promote the development of community pension in China.

\section{3) Market_—Paid Provision of Old-age Services}

Introducing the market into the community pension service can not only develop the market advantages of pursuing efficiency and maximizing economic benefits, but also can integrate social resources, which can exert market's strength in public service and realize social benefits. Community pension service enterprises can meet multiple needs of different old people and make the pension services more targeted and professional by providing multiple and diversified services for elderly in the community. In order to promote the development of the old-age industry, the government began to purchase pension services and to provide supportive policies and financial subsidies to enterprises. This behavior provides good opportunities for enterprises to be survival and development. According to the different needs of the elderly, home-based old-age service enterprises provide many kinds of services, such as catering, housekeeping, medical care and maintenance. The cost of the service is paid by the government financial subsidy and personal money.

\section{4) The Volunteer Organization_-Voluntary Service}

As social public welfare organizations, voluntary organizations aimed to provide services to our society and promote the harmony of our society. Voluntary work has the basic characteristics of public welfare, voluntary, unpaid and organized. With the growth of social power, volunteer organizations are becoming more and more perfect and can play their own role in pension services. Volunteer organizations can provide volunteer services for old people, such as chatting, simple care, housekeeping, study, entertainment and so on, and these organizations can also make the elderly feel humanistic care and spiritual comfort, let the elderly feel the warmth of love, even though these services are less professional than businesses and specialized agencies.

5) Community Elderly Residents—Self-help and Mutual Assistance

We usually think that our government, community and social organizations should provide service to old people which are the object of pension service. From another view, we can think old people in the community can take care of each other. Old people understand what the needs of themselves, they can obtain understanding from peers. Elderly groups can also take care of each other. Some elderly groups can achieve needs such as social association, entertainment and physical exercise by taking part in some group activities which also meet part of the needs of pension.

\section{B. Role setting of multiple subjects}

The Multi-governing community pension service model is shown in Fig.1. It shows that government, communities, market, volunteer organization and the elderly residents maintain close relationship under the Cooperation and Cogovernance Mode of Urban Communities Providing for the Aged. The community plays a key role in Cooperation and Co-governance Mode of Urban Communities Providing for the Aged .Communities plays the role of leader and coordinator by integrating resources and coordinating relationships to provide pension service for elderly. The government is the policy maker of community pension service and provides preferential policies and financial support to the community and social organizations. The market provides paid services for the elderly in the community, while volunteer organizations provide voluntary services for the elderly. In this model, the government formulate pension policy, which is implemented by the community and feedback to the government in time; the community provides old-age services for the elderly and manages the information of the elderly, and maintains long-term liaison and cooperation with the social organization such as markets. The government provides preferential policy and financial subsidies to the market and volunteer organizations that provide pension service for the elderly, and controls the provision of the community pension service .Besides that, market provides aged-care at home and volunteer organization provide multiple pension service. 


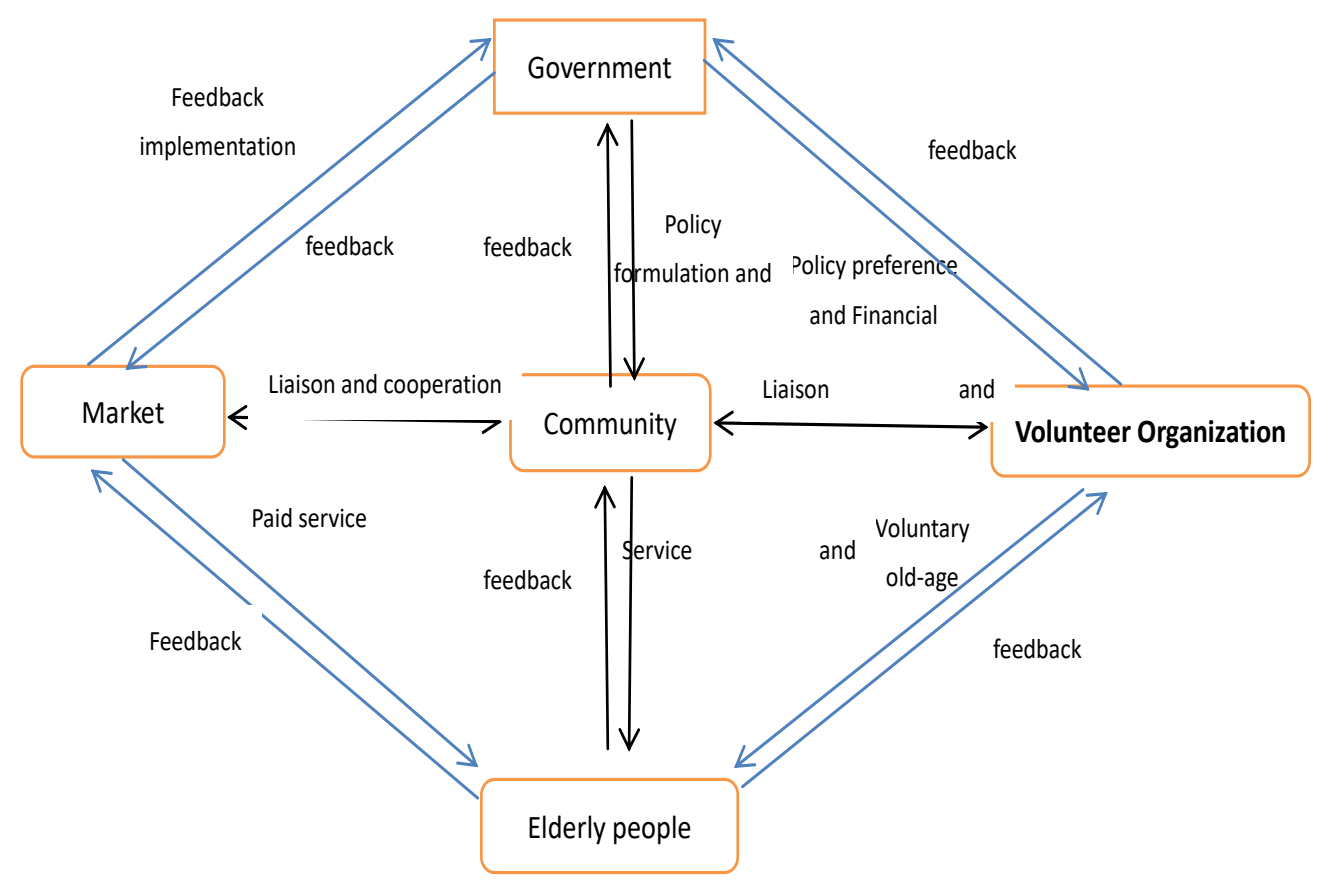

Fig. 1. The relationship among subjects under the Multi-governing community pension service model

Cooperation and Co-governance Mode of Urban Communities Providing for the Aged has outburst features by integrating resources among governments, communities, social organizations and residents. These subjects provide pension service together and realize social governance. At the same time, our community pension service can be supplied effectively and the system of pension service can be established by confirming functions and relationships between these subjects. Cooperation and Co-governance Mode of Urban Communities Providing for the Aged which has multiple subjects allows the elderly to enjoy a more diversified pension service and meets the needs of the elderly in life and spirit.

\section{CONCLUSION}

In summary, with the aggravation of aging in our country, community old-age support has become an important trend to deal with "aging" and solve the problem of pension in China at present and in the future. In order to provide better community pension service, this paper explores the model of community pension service by combining theory and practice. Based on the theory of governance, multi-center theory and Maslow's hierarchy of needs, combined with the current situation and problems of community old-age service model in Changchun, we puts forward Cooperation and Co-governance Mode of Urban Communities Providing for the Aged. The main connotation of this model is that the government, the community, the social organization and the residents provide pension service together and construct an new system of pension service community-centered. Under the Cooperation and Co-governance Mode of Urban Communities Providing for the Aged, the government, community, market, volunteer organizations and the elderly residents have their own roles and maintain close contact. In order to optimize the Cooperation and Co-governance Mode of Urban Communities Providing for the Aged and to solve the problems existing in the current community pension service effectively, the paper puts forward some relevant measures which contains relationship between the government and the market can be straightened out, the establishment of cooperative pension service and professional development of the pension service.

\section{REFERENCES}

[1] Keping Yu, "Governance and Good Governance," Social Science Literature., 2005. (In Chinese).

[2] Youmei Li, "Urban Social Governance,"Social Science Literature.2014. (In Chinese).

[3] Yuming Lei ,Bo Cao,and Jing Li,"Cooperation and Co-governance Mode of Urban Communities Providing for the Aged in Vision of Public Service-oriented Government".Journal of Huazhong Agricultural University, pp 113-118.April 2013. (In Chinese).

[4] Kai Ma and Fengzhi Liu,"The Analysis of the Model of Provision for the aged in Community in Social Network Embedded Perspective,".Journal of Sichuan University of Science\&Engineering, pp.38-41, February 2011. (In Chinese).

[5] Jin Li, "Research of the Living Conditions and Demand for Community Service of Old People Living at home in City._- Taking Shanghai as an Example," East China University Of Science.2014. (In Chinese) 